\title{
Disability in young adults: the role of injuries
}

\author{
Maggie Barker, Chris Power
}

\begin{abstract}
Study objective-To describe the prevalence of disability in young adults and estimate the contribution that injuries make to disability. Design-The study uses data from a British longitudinal survey, the National Child Development Study (1958 cohort). Disability at age 23 was ascertained from three questions asked in an interview with cohort members in 1981: these related to longstanding illness that limits activity, permanent disability following an accident after age 16, and registered disability. Lower and upper estimates of the contribution of injuries to disability were derived from ICD-9 codes allocated to the disabilities.
\end{abstract}

Subjects-These comprised 12537 subjects, representing $76 \%$ of the target population, cohort members still alive and resident in Britain in 1981.

Main results-Prevalence of disability according to the three definitions was: 46 per 1000 with limiting longstanding illness; 28 per 1000 with a permanent accident related disability of onset after age 16; and 10 per 1000 registered disabled. Combining all three definitions, the overall prevalence of disability was 68 per 1000 , with men reporting more disability than women. It was estimated that an injury caused the disability for $16.7 \%$ of subjects, at the lower estimate, and $26.0 \%$ at the upper estimate $(23 \cdot 1 \%$ to $32 \cdot 1 \%$ for men and $8.6 \%$ to $18 \cdot 4 \%$ for women). For limiting longstanding illness of onset after 16 , between $33.5 \%$ and $47.8 \%$ was due to an injury. Road accidents caused $31 \%$ of permanent accident related disability. Over one half of men and nearly three quarters of women reporting permanent accident related disability had not been admitted to hospital for their injury. Conclusions-Injuries are an important cause of disability in young adults, particularly injuries resulting from accidents after age 16. Accident prevention in the 16-24 group has the potential to reduce the prevalence of disability substantially.

f Epidemiol Community Health 1993; 47: 349-354

Injuries are a major cause of death and short term morbidity in children and young adults, and might be expected to make an important contribution to long term disability in the young. It is not clear, however, what proportion of disabilities in young people are due to injury. ${ }^{1}$ This is an important gap in our knowledge, leaving unanswered such questions as the true cost to society of injuries and the potential impact of injury prevention on the over- all burden of disability. It also precludes adequate assessment of the health needs of young people in the community who are disabled as a result of injury.

In Britain, routine health service information systems do not allow an estimate of the prevalence of disability, nor of the contribution of injury to disability. The main sources of information on disability are the General Household Surveys (GHS), conducted annually, and the Office of Population Censuses and Surveys (OPCS) Disability Surveys, carried out between 1985 and $1988 .^{2}{ }^{3}$ The GHS, based each year on a sample of the general population resident in non-instititional households in Great Britain, includes questions about chronic sickness. In 1989,110 per 1000 16-44 year olds reported disability that limited their activities, a proportion that has remained fairly constant since the early 1970s. The OPCS Disability Surveys estimated that 21 per 1000 16-19 year olds and 29 per $100020-29$ year olds were disabled, with an overall prevalence of 142 for adults over 16. Estimation of the contribution of injury to disability is only possible for the first year of the GHS, 1971, when cause of disability was recorded. In that year, 89 per 1000 15-44 year olds in England and Wales reported limiting longstanding illness, and of these, $15 \cdot 1 \%$ were caused by an injury.

Britain is not the only country with poor information. The report on a World Health Organisation symposium, The epidemiology of accident traumas and resulting disabilities, commented that: "Above all it is rarely possible to know the initial cause of handicap: accident, illness or congenital condition." and "... no health system appears to be capable of calculating the impact of accidents ... on the overall disability figures in a given community." 4

Special studies to estimate the contribution of injury to disability are rare. They tend to be based on selected populations of disabled subjects, such as children in special schools or on disability registers, ${ }^{56}$ or to focus on certain types of disability. ${ }^{7}$

The present paper estimates the prevalence of disability in a large nationally representative sample of young British adults and assesses the contribution made by injuries. Throughout, the term injury is used to include both intentional and unintentional injury or poisoning. "Accident" is used for the event that results in an unintentional injury.

\section{Methods}

STUDY SAMPLE

This paper uses data from the National Child Development Study (NCDS), which started as the Perinatal Mortality Survey, with all children born in England, Scotland, and Wales in the week 3-9 March $1958 .{ }^{8}$ Information was obtained shortly after birth on 17414 babies, $98 \%$ of the 
target sample. There have been five follow up contacts, at ages $7,11,16,23$, and $33 .{ }^{910}$ Immigrants born in the relevant week were included in the sweeps at ages 7,11 , and 16 .

The data described here were drawn exclusively from the 1981 survey, an interview with the 12537 cohort members traced at age 23 . Although response had declined to $76 \%$ of all study members still alive and resident in Britain in $1981,{ }^{11}$ the sample is still in general representative of the original birth cohort. However, certain disadvantaged groups are known to be under-represented, which may, in particular, lead to an underestimation of the prevalence of disability. For example, children with chronic illness identified by age 7 were under-represented in the 23 year follow up. ${ }^{12}$

\section{DEFINITIONS OF DISABILITY}

Three definitions of disability were adopted, based on three questions in the interview questionnaire.

\section{(1) Limiting longstanding illness}

The primary definition of disability was based on the question "Do you have any longstanding illness, disability, or infirmity which limits your activities in any way compared with people of your own age?". Enquiry was made about the age of onset and the nature of the condition, which was coded according to the International Classification of Diseases, 9th revision (ICD-9), ${ }^{13}$ for up to two disabilities.

(2) Permanent accident related disability (onset age 16-23)

Questions about accidents since age 16 which resulted in a hospital attendance were followed by "Has this (have any of these) accident resulted in any permanent disability?". Again the nature of the disability was coded using ICD-9, and up to two disabilities per person were recorded. Where two disabilities were mentioned, the ICD disability code and the injury code (see below) were examined to determine whether they related to the same injury or to two separate traumas.

\section{(3) Registered disabled}

At the beginning of the interview, subjects reported whether they were registered as a disabled person. (Those who answered in the negative were then asked the limiting longstanding illness question. This question was repeated for all subjects later in the interview, and definition (1) refers to this second occasion. All who answered in the affirmative on the first occasion did so again on the second.)

\section{ACCIDENT MEASURES}

Information was obtained on the number of accidents between the ages of 16 and 23 years requiring hospital admission or attendance at outpatients or casualty. The following were established for the first eight accidents mentioned:

(i) Age at accident.

(ii) Type of accident: road as pedestrian; road as any other type of road user; at work; at home; sports; other.

(iii) Admitted to hospital or outpatient.

(iv) Type of injury: coded using a system derived from the "Injury and Poisoning" chapter of ICD-9.

When a subject who reported a permanent accident related disability (onset 16-23) had had more than one accident, the disability and injury codes were matched in order to determine which accident had caused the disability. This was necessary because the questions were not linked directly.

MEASURES OF INJURY RELATED DISABILITY

(1) Limited longstanding illness: ICD code categories The ICD codes allocated to limiting longstanding illness (disability definition (1)) were grouped into three categories of likelihood that the disability had resulted from an injury.

(i) Certain injury: disabilities with a code in the ICD chapter "Injury and Poisoning" (ICD 800-995) were considered to be certainly the result of trauma. ${ }^{13}$

(ii) Possible injury: certain "Diseases of the Musculoskeletal System and Connective Tissue" (ICD codes specified in table 1) fit injury related conditions.

(iii) Not injury: all other codes were assigned to a non-injury group.

Table I Injury related ICD-9 codes in chapter on "Diseases of the Musculoskeletal System and Connective Tissue"

716 Other and unspecified arthropathie

717 Internal derangement of knee

718 Other derangement of joint

719 Other and unspecified disorder of joint

721 Spondylosis and allied disorders

722 Intervertebral disc disorder

723 Other disorders of the cervical region

724 Other and unspecified disorders of the back

726 Peripheral enthesopathies and allied syndromes

727 Other disorders of synovium, tendon, and bursa

729 Other disorders of soft tissue

733 Other disorders of bone and cartilage

735 Acquired deformities of toe

736 Other acquired deformity of limbs

738 Other acquired deformity

(2) Permanent accident related disability (onset age 16-23)

Disability definition (2) is also a direct measure of injury related disability, albeit limited to accidental injury occurring after the subject's 16th birthday. (Respondents were not specifically asked about disability caused by an accident before the age of 16 nor about intentional injury.)

\section{DATA ANALYSIS}

Prevalence estimates of disability were calculated for each of the three definitions.

Lower and upper estimates of the contribution of injuries to limiting longstanding illness (disability definition (1)) were derived using the two measures of injury related disability. The lower estimate was based on individuals with a limiting longstanding illness for whom it was certain that an injury was the cause (or, in the case of those with two disabilities, an injury caused one of them). They were identified (a) from measure (1), as subjects whose limiting longstanding illness was given a "certain injury" ICD code, and (b) from measure (2), as subjects who actually reported that their limiting longstanding illness was a permanent accidentrelated disability (onset 16-23). The upper estimate was derived using measure (1), by including subjects with limiting longstanding illness given a "possible injury" ICD code (table I).

\section{Results}

PREVALENCE OF DISABILITY

The three prevalence estimates of disability are 46 per 1000 with limiting longstanding illness (defi- 
Table II Prevalence of disability in the National Child Development Study cohort at age 23 years National Child Development Study cohort members at age 23 years
Figure: Disability in

nition (1)); 28 per 1000 with permanent accident related disability (onset 16-23) (definition (2)); 10 per 1000 registered disabled (definition (3)) (table II).

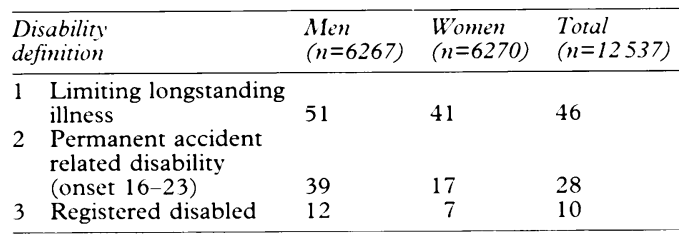

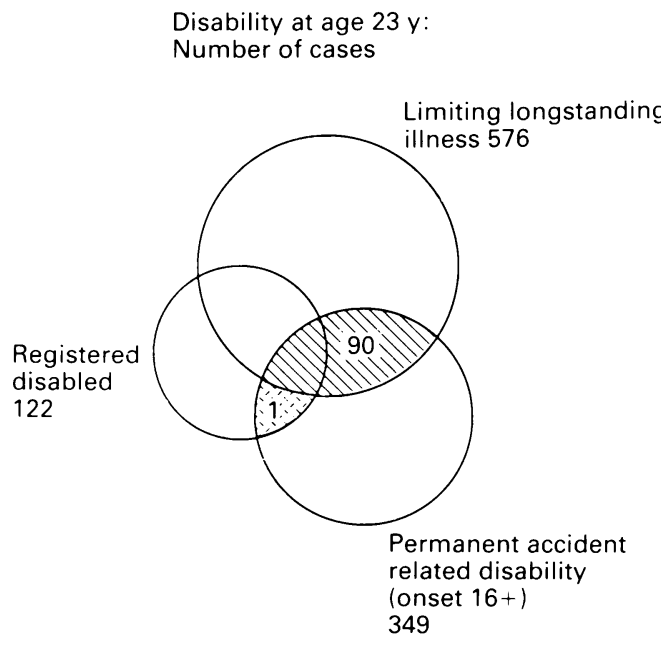

By all estimates, more men reported disability than women. Men accounted for just over half $(56 \%)$ of the 576 subjects identified by definition (1); over two thirds $(70 \%)$ of the 349 subjects identified by definition (2); and almost two thirds $(61 \%)$ of the 122 identified by definition (3).

The figure illustrates the extent to which the three definitions of disability overlap. Almost three quarters (258) of the cohort members with a permanent accident related disability did not report earlier in the interview that they had a limiting longstanding illness. Most of the registered disabled reported having a limiting longstanding illness, but 17 out of 122 did not.

Thus, using the three definitions, a core of 851 cohort members reporting disability has been ascertained, that is, 68 per 1000 of the population

Table III Conditions resulting in limiting longstanding illness (576 subjects reported 637 conditions

\begin{tabular}{|c|c|c|c|c|c|c|}
\hline \multirow[b]{2}{*}{ ICD-9 category } & \multirow{2}{*}{$\begin{array}{l}\text { Men } \\
\text { No. }\end{array}$} & \multirow[b]{2}{*}{ Ratef } & \multicolumn{2}{|l|}{ Women } & \multirow{2}{*}{$\begin{array}{l}\text { Total } \\
\text { No. }\end{array}$} & \multirow[b]{2}{*}{ Rate } \\
\hline & & & & Rate & & \\
\hline Infections (1-139) & 1 & (2) & 3 & (5) & 4 & (3) \\
\hline Neoplasms (140-239) & 2 & (3) & 3 & (5) & 5 & (4) \\
\hline Endocrine, nutritional, & & & & & & \\
\hline metabolic, immunity (240-279) & 11 & (18) & 8 & (13) & 19 & (15) \\
\hline Blood and blood-forming organs $(280-289)$ & 2 & (3) & 2 & (3) & 4 & (3) \\
\hline Mental disorders $(290-319)$ & 27 & (43) & 46 & (73) & 73 & (58) \\
\hline Nervous system and & & & & & & \\
\hline sense organs $(320-389)$ & 79 & (126) & 58 & (93) & 137 & (109) \\
\hline Circulatory $(390-459)$ & 6 & (10) & 6 & (10) & 12 & (10) \\
\hline Respiratory $(460-519)$ & 46 & (73) & 41 & $(65)$ & 87 & (69) \\
\hline Digestive (520-579) & 13 & (21) & 7 & (11) & 20 & (16) \\
\hline Genitourinary (580-629) & 3 & (5) & 9 & (14) & 12 & (10) \\
\hline Complications of pregnancy and & & & & & & \\
\hline $\begin{array}{l}\text { birth }(630-676) \\
\text { Skin and subcutaneous tissue }(680-709)\end{array}$ & - & - & 2 & (3) & 2 & (2) \\
\hline Skin and subcutaneous tissue $(680-709)$ & 10 & (16) & 8 & (13) & 18 & (14) \\
\hline $\begin{array}{l}\text { Musculoskeletal and } \\
\text { connective tissue }(710-739)\end{array}$ & 50 & $(80)$ & 34 & (54) & 84 & \\
\hline Congenital/perinatal $(740-779)$ & 21 & (33) & 24 & $(38)$ & $\begin{array}{l}44 \\
45\end{array}$ & $\begin{array}{l}(67) \\
(36)\end{array}$ \\
\hline Injury and poisoning (800-995) & 52 & (83) & 19 & (30) & 71 & (57) \\
\hline Other & 12 & (19) & 11 & (18) & 23 & (18) \\
\hline
\end{tabular}

* Of 6270 men and 6268 women. Where two conditions in the same ICD category are reported by one person they are counted once only.

tPrevalence rates per 10000
CONTRIBUTION OF INJURY TO LIMITING LONGSTANDING ILLNESS AT AGE 23

We now give lower and upper estimates of the contribution of injuries to limiting longstanding illness, using the two measures of injury related disability (see method).

The lower estimate is comprised of subjects reporting limiting longstanding illness for whom it is certain that an injury was the cause. Altogether $12.3 \%$ of the 576 cohort members who reported limiting longstanding illness had at least one with an injury ICD code- $16 \cdot 2 \%$ of men compared with $7.5 \%$ of women (table IV). (Table III gives the overall distribution of ICD-9 codes allocated.)

Table IV Proportion of limiting longstanding illness due to injury

\begin{tabular}{lccc}
\hline & $\begin{array}{l}\text { Men } \\
(n=321)\end{array}$ & $\begin{array}{l}\text { Women } \\
(n=255)\end{array}$ & $\begin{array}{l}\text { Total } \\
(n=576)\end{array}$ \\
\hline $\begin{array}{llll}\text { Lower estimate: } \\
\text { Measure 1 -injury ICD code }\end{array}$ & $23 \cdot 1$ & $8 \cdot 6$ & $16 \cdot 7$ \\
Measure 2-permanent & & $7 \cdot 5$ & $12 \cdot 3$ \\
$\quad \begin{array}{l}\text { accident related disability } \\
\text { Upper estimate: }\end{array}$ & $6 \cdot 9$ & $1 \cdot 1$ & $4 \cdot 4$ \\
$\quad \begin{array}{l}\text { Lower estimate } \\
\text { Measure 1-ICD code in }\end{array}$ & $32 \cdot 1$ & $18 \cdot 4$ & $26 \cdot 0$ \\
table I & $9 \cdot 1$ & $8 \cdot 6$ & $16 \cdot 7$ \\
& $9 \cdot 0$ & $9 \cdot 8$ & $9 \cdot 3$ \\
\hline
\end{tabular}

From information recorded for subjects who reported both a limiting longstanding illness and a permanent accident related disability it was possible to identify a further $4 \cdot 3 \%$ whose disability was caused by injury. Hence a lower estimate of $16.7 \%$ was derived $-23.1 \%$ for men and $8.6 \%$ for women (table III).

The upper estimate was derived by adding to the lower estimate subjects whose limiting longstanding illness had an ICD code in the "possible injury" category (table I). Thus, as an upper estimate, $26 \cdot 0 \%$ of subjects with a limiting longstanding illness had an injury as the cause- $-32 \cdot 1 \%$ of men and $18.4 \%$ of women (table III).

Sixty one of the 576 subjects with limiting longstanding illness reported two separate conditions. In terms of disabilities rather than disabled individuals, at the lower estimate $16.0 \%$, and at the upper estimate $25 \cdot 1 \%$, of disabilities were due to injury.

CONTRIBUTION OF INJURY TO LIMITING LONGSTANDING ILLNESS OF ONSET BETWEEN THE AGES OF 16 AND 23

Table $\mathrm{V}$ shows the age of onset of disability (definition (1)) classified according to the likelihood of injury being the cause. For subjects included in the lower estimate, with a disability known to be a result of injury, $85.4 \%$ had an onset after age 16 (and only four subjects had had their disabling injury before the age of 10). Using the upper estimate, $78 \%$ of subjects had an age of onset after 16 (with $64 \cdot 8 \%$ of subjects with a "possible injury" ICD code having onset after 16). The distribution of age of onset for the remainder of subjects reporting limiting longstanding illness (most of which was probably not injury related) was more evenly spread across age groups.

Thus, of cohort members who reported that their limiting longstanding illness began after age 16 , at least a third $(33.5 \%$ at the lower estimate, rising to $47 \cdot 8 \%$ at the upper estimate) resulted from injury. 
Table $V$ Age at onset of limiting longstanding illness (\%)

\begin{tabular}{lllll}
\hline & Age $(y)$ & & \\
\cline { 2 - 5 } Limiting longstanding illness & Birth $-<1$ & $1-15$ & $16-23$ & Not known \\
\hline Injury related: & 0 & $13 \cdot 5$ & $85 \cdot 4$ & $1 \cdot 0$ \\
Lower estimate $(\mathrm{n}=96)$ & 0.7 & $20 \cdot 7$ & $78 \cdot 0$ & $0 \cdot 7$ \\
Upper estimate $(\mathrm{n}=150)$ & $32 \cdot 4$ & $34 \cdot 3$ & $30 \cdot 0$ & $3 \cdot 3$ \\
Not injury related $(\mathrm{n}=426)$ & &
\end{tabular}

CONTRIBUTION OF INJURY TO DISABILITY DEFINED AS EITHER LIMITING LONGSTANDING ILLNESS OR PERMANENT ACCIDENT RELATED DISABILITY (ONSET 16-23)

Of the 835 cohort members identified from disability definitions (1) and (2) taken together (figure), at the lowest estimate $44.4 \%$ (371) had a disability resulting from injury. Of the 516 with onset after age $16,69 \cdot 6 \%$ (359) had an injury related disability.

TYPE OF ACCIDENT CAUSING DISABILITY

It is only possible to distinguish the type of accident for the 349 cohort members with permanent accident related disability (onset 16-23), who reported 359 separate accidents resulting in disability. A total of $31 \%$ were road accidents, most non-pedestrian $(91 \cdot 1 \%)$ (table VI). The next commonest types of accident to cause disability were, for men, those taking place at work $(24.8 \%)$, and, for women, accidents classified as "other" $(20 \cdot 0 \%)$.

MEDICAL CARE RECEIVED FOR ACCIDENTS CAUSING DISABILITY

Of the 359 conditions reported as permanent accident-related disabilities, a higher proportion were caused by injuries treated in an outpatient setting only ( $54 \cdot 3 \%$ for men; $73 \cdot 3 \%$ for women) than those resulting in admission to hospital.

However, hospital inpatient treatment was more common in the 70 subjects who reported that their permanent accident related disability (onset 16-23) was also a limiting longstanding illness $(75 \cdot 0 \%$ for men; $50.0 \%$ for women).

\section{Discussion}

In any description of disability, the definition is clearly of central importance. The World Health Organisation has emphasised that confusion over terminology in this area is a major problem, and has recommended that the International Classification of Impairments, Disabilities and Handicaps $(I C I D H)$ should be adopted in disability research. ${ }^{414}$ The disability criteria adopted here were dictated by the wording of the NCDS interview questionnaire and ascertainment of disability was through self-reporting. Thus words such as "illness, disability, or infirmity" meant whatever the subject took them to mean. Such interpretation depends on knowledge, attitudes, and judgements that are to some extent influenced by social background, level of education, and expectations in life. In addition, availability of services, or, in the case of injury, recourse to compensation, may prompt awareness of a disability. Some subjects will be less willing than others to adopt a sickness role. When questioned about the nature of the disability, this may be interpreted either as "What caused it?" or "What are the symptoms or limitations?". With the first meaning, individuals may falsely attribute a cause to the condition. For example, the urge to explain symptoms may result in the link being made with a past injury, in the absence of any evidence that the two are connected. The second interpretation may prompt a response from which it is impossible to discern aetiology - for instance, back pain. Such problems are common to studies that ascertain disability through self reporting, including the GHS. Difficulties involved in seeking a cause of disability led to the GHS abandoning this approach and concentrating on symptoms. ${ }^{15}$

The primary definition of disability used in this paper is based on the limiting longstanding illness question of the NCDS questionnaire. This is similar to the question on limiting disability asked each year in the GHS ("Do you have any longstanding illness, disability, or infirmity? . . . Does this illness or disability limit your activities in any way?"), which is generally taken as a proxy for disability. Among the NCDS cohort in 1981, the

Table VI Permanent accident related disability (onset 16-23). Percentage of different accident types causing disability

\begin{tabular}{lccc}
\hline Accident type & $\begin{array}{c}\text { Men } \\
(n=254)\end{array}$ & $\begin{array}{c}\text { Women } \\
(n=105)\end{array}$ & $\begin{array}{c}\text { Total } \\
(n=359)\end{array}$ \\
\hline Road-pedestrian & $2 \cdot 8$ & $7 \cdot 6$ & $4 \cdot 2$ \\
Road-other & $28 \cdot 3$ & $23 \cdot 8$ & $27 \cdot 0$ \\
Work & $24 \cdot 8$ & $17 \cdot 1$ & $22 \cdot 6$ \\
Home & $7 \cdot 9$ & $14 \cdot 3$ & $9 \cdot 7$ \\
Sports & $19 \cdot 7$ & $12 \cdot 4$ & $17 \cdot 5$ \\
Other & $9 \cdot 1$ & $20 \cdot 0$ & $12 \cdot 3$ \\
Not known & $7 \cdot 5$ & $4 \cdot 8$ & $6 \cdot 7$ \\
\hline
\end{tabular}

rate of limiting longstanding illness was 46 per 1000. This is lower than the 1981 GHS estimates of 100 per 1000 for $16-44$ year olds and 70 per 1000 for the $5-15$ age group. ${ }^{16}$ The NCDS rate is, however, higher than that found by the OPCS Survey of Disability (29 per 1000 20-29 year olds), which based its definitions on the WHO ICIDH. ${ }^{3}$ These discrepancies may be partly explained by response bias, with disabled children in NCDS being under-represented in the subsequent follow ups of the cohort. ${ }^{12}$ However, it is likely that other surveys would also be affected by such biases.

Comparison of prevalence rates between surveys must be treated with caution. As NCDS data illustrate, self reported disability is highly sensitive to context and wording. For example, fewer people declared a limiting longstanding illness on the first occasion that they were asked, right at the start of the interview and straight after a question on registered disability, than on the second. Almost three quarters of those who reported a permanent accident related disability had not cited it as a limiting longstanding illness earlier in the interview. Perhaps the accident related disability did not "limit activities", or was not judged to be "longstanding". Alternatively, the questions on accidents that immediately preceded the accident related disability question may have prompted mention of a relatively minor disability. There is some evidence that subjects who reported their accident related disability as a limiting longstanding illness had injuries that were more severe, since $70 \%$ were admitted to hospital compared with only $38 \%$ of the others. However, the hospital admission itself may have made the event and subsequent disability more memorable. 
The register of disabled persons is required under the Disabled Persons Employment Act 1944. To qualify, a disabled individual must want a job and be reasonably employable. The disability must be anticipated to last at least one year and be an obstacle to employment. It is left to the individual to decide whether or not to register, and as our results show, many do not do so. This is a highly selective definition of disability, and it is not surprising that it provides the lowest estimate of prevalence of disability among cohort members at age 23 .

The OPCS Disability Survey found that the prevalence of disability in children was higher for boys than girls. The prevalence for women began to exceed that for men in the 20-24 age group, remaining higher than for men throughout the rest of adulthood. ${ }^{3}$ The findings of the GHS are similar. Among 23 year olds in the NCDS, the limiting longstanding illness rate was slightly higher for men than for women. However, the prevalence of permanent accident related disability was twice as high in men than women. Injury related disability could account, therefore, for the differential between men and women in early adulthood. This is consistent with the much higher injury mortality in young men in early adulthood (for example, in 1980 in England and Wales, the injury mortality was 588 per million men aged 15-24 compared with 164 per million women. ${ }^{17}$ Death rates have fallen since then, but the gender differential persists). From the NCDS data we have also found that accidents are more common in men and that the risk of permanent disability after an accident increases with the number of accidents experienced (unpublished data).

In estimating the contribution of injury, we have taken limiting longstanding illness as the primary definition of disability. At the lower estimate, $16 \cdot 7 \%$ of cohort members with limiting longstanding illness (23. $1 \%$ of men and $8.6 \%$ of women) were disabled as the result of an injury. Undoubtedly, this is an underestimate. It includes two groups. Firstly, those with an ICD code in the "Injury and Poisoning" chapter. Clearly this does not cover all possible injury related disabilities. ICD codes ascribed to conditions reported as permanent accident related disabilities illustrate this. Although $90 \%$ fell in the "Injury and Poisoning" chapter, a further $6 \%$ were in "Diseases of the musculoskeletal system and connective tissue", and the remainder were coded in other chapters (for example, organic brain damage, paralytic syndromes, signs and symptoms involving the head and neck). Other research using NCDS data has found that the cohort includes, for example, subjects with post-traumatic epilepsy. ${ }^{18}$ Secondly, the lower estimate includes those who reported the same disability twice, both as a limiting longstanding illness and as a permanent disability due to an accident after their 16th birthday. This ascertained some of the injury related, limiting longstanding illness that did not have an injury ICD code, but would not pick up injury related disability not considered to be "permanent", disability due to accidents before age 16 , or disability due to intentional injury.

At the upper estimate, a third of disabled 23 year old men and a quarter of disabled women were disabled due to injury. This estimate was derived by including musculoskeletal and connective tissue ICD codes judged to be consistent with injury related disability. Selection of "injury related musculoskeletal codes" (table I) was to some extent arbitrary. Some of the categories in the list are, in this age group, highly likely to represent traumatic conditions (for example, ICD 717: "internal derangement of knee"). Others include some codes that are specifically trauma related and others that are not (for example, ICD 716: "other and unspecified arthropathy", includes traumatic arthopathy; 733: "other disorders of bone and cartilage", includes malunion and non-union of fracture). The ICD codes allocated to the $6 \%$ of permanent accident related disabilities coded from the "Diseases of the musculoskeletal system and connective tissue" chapter are all included in our list of injury related musculoskeletal codes. Clearly, this approach will misclassify some limiting longstanding illnesses as being injury related when they are not. However, this will be counterbalanced to some extent by inability to identify the injury related disability from other ICD chapters.

Estimation of the contribution of injury to disability is only possible for the first year of the GHS (1971) when the cause of the disability was recorded. In that year, 89 per 1000 15-44 year olds in England and Wales reported a limiting longstanding illness, and of these, $15 \cdot 1 \%$ were caused by an injury-close to our lower estimate. Similarly, the WHO estimates that worldwide, across all ages, $15 \%$ of disability is caused by injury. ${ }^{4}$ For example, in The Netherlands, 87 per 1000 of the total population were found to have a handicap (defined as one or more major functional disorders), and of these, $15 \cdot 1 \%$ of men and $11.4 \%$ of women were handicapped as the result of an accident. ${ }^{4}$ (The greater sex discrepancies shown in the present study are likely to be explained by the age group under consideration here.)

Only $2 \cdot 6 \%$ of all children registered as handicapped in the Canton of Berne, Switzerland, had had an accident as the main cause of their handicap (with around half due to traffic accidents). It was concluded, therefore, that accidents are of minor importance as a cause of handicap in childhood compared with genetic, prenatal, or perinatal causes. ${ }^{5}$ Similarly, in Sweden, of 266 children aged 4 to 16 years on a county register for motor handicap, $3.4 \%$ had disabilities resulting from trauma. ${ }^{6}$ Fractures and "similar disabilities" were specifically excluded. Both studies dealt only with the most severely handicapped children-that is, those needing special education. The sequelae of injury to the nervous system were reported for a birth cohort of 12058 children born in two provinces of Finland followed up to age $14 .^{7}$ Injuries were responsible for only $3.2 \%$ of the 495 children in the cohort with cerebral palsy, epilepsy, or mental retardation.

From such studies it has been concluded that the total effect of accident prevention on the prevalence of disability in children would be marginal. However, the present paper suggests that a reduction in injuries in adolescence would more substantially reduce the number of young adults with a disability. This is illustrated by focusing on disability of onset between the ages 16 and 23. Between a third and nearly a half of subjects with onset of disability after age 16 had an injury as the cause. Accidents occurring before age 16 make a smaller contribution to disability at 23 than those that are more recent. This may be partly due to recall bias (more recent injuries are more likely to be reported), although recent onset disability of short duration was not 
covered by the question, which asked about permanent, accident related disability. Furthermore, the findings are consistent with the pattern of injury mortality, which is much higher in early adulthood than in childhood. ${ }^{17}$

The NCDS was not designed solely for the purpose of investigating injury related disability, and inevitably there are limitations. Additional information about accidents resulting in disability (such as the type of accident and medical treatment) was available only for those who reported a permanent accident related disability. Even for this group, it was difficult to identify the accident responsible for the disability. In order to link disabilities with accidents a detailed matching of disability ICD codes and accidental injury codes (also based on ICD-9) was necessary. Subjects gave details of up to eight accidents and reported up to two accident related disabilities. Road accidents caused nearly a third of permanent accident related disabilities (onset 16-23). Nine per cent were to pedestrians, the remainder to other road users. Unfortunately the interview question did not disaggregate pedal cyclists, riders of motorbikes, and car occupants. Among the 70 subjects whose permanent accident related disability was also reported as a limiting longstanding illness, over a third (43\%) were due to road accidents. These data relate to a period before 1983, when seat belt wearing became law in Britain for drivers and front seat passengers of cars and vans. This legislation led to a decrease in the number of front seat, car occupant casualties. ${ }^{19}$ However, it is not clear what the impact has been on the numbers of road accident victims with long term sequalae. Similarly, improvements in trauma care in recent years may have led to an increase in the numbers who survive with a disability.

What is clear from this study is that much disability is caused by injuries that require outpatient treatment only. Over one half of men and nearly three quarters of women with permanent, accident related disabilities had not been admitted to hospital. Studies using hospital admission as a threshold of severity in terms of the likelihood of long term disability are therefore likely to underestimate residual effects.

Thus, data from the large nationally representative sample in the NCDS provide an estimate of the contribution that injuries make to disability in young adults. As much as a quarter of all limiting longstanding illness at age 23 may result from injury, with injuries in early adulthood playing a greater part than those in childhood. That injuries have their major impact in early adulthood is to be expected. During infancy and early childhood, congenitally acquired conditions play a major role, whereas, later in life, chronic diseases such as arthritis, stroke, coronary heart disease, and bronchitis are common causes of impairment. The public health message is clear. Much disability in young adults is preventable. Often primary accident prevention initiatives are focused on the under $15 \mathrm{~s}$. It is important that a higher profile be given to injury prevention in young adults. The Government's Health of the Nation strategy, which has selected accidents as a key area for health improvement, has set a target for reducing mortality from accidents among $15-24$ year olds by $25 \%$ by the year 2005 , based on 1990 levels. $^{20}$ A benefit of successful accident prevention initiatives towards achieving this target would be a significant reduction in long term disability, particularly in men.

This work was funded by the Wolfson Foundation and North West Thames Regional Health Authority. We are grateful to support staff at the Social Statistics Research Unit, City University, London, for access to the NCDS data.

1 Manciaux M, Romer CJ, eds. Accidents in childhood and adolescence: the role of research. Geneva: World Health adolescence: the role of research.
Organisation/INSERM, 1991.

2 Orfice of Population Censuses and Surveys. General Office of Population Censuses and Surveys. General
Household Survey. Series GHS. London: HMSO, annual. 3 Martin J, Meltzer H, Eliot D. The prevalence of disability among adults. OPCS Surveys of Disability in Great Britain. Report 1. London: HMSO, 1989.

4 World Health Organisation. The epidemiology of acciden traumas and resulting disabilities. Report on a WHO symposium, Strasbourg 19-21 March 1981. EURO Reports and Studies 57, Copenhagen: WHO Regional Office for Europe, 1982: 28 .

5 Vuille J. Accidents as a cause of disability and handicap. In: Kohler L, Jackson H, eds. Traffic and children's health. Stockholm, Sweden: The Nordic School of Public Health, 1987: $57-70$.

6 Lagergren J. Children with motor handicaps. Acta Paediatric Lagergren J. Children with
Scand 1981;289 Suppl.

7 Rantakallio $P$, Wendt $L$ von. Trauma to the nervous system and its sequelae in a one-year birth cohort followed up to the age of 14 years. F Epidemiol Comm Health 1985; 39: 353-6.

8 Butler NR, Bonham DG. Perinatal mortality. Edinburgh: Livingstone, 1963

9 Davie R, Butler NR, Goldstein H. From birth to seven. London: Longman in association with National Children's Bureau, 1972.

10 Fogelman K, ed. Growing up in Great Britain. London Macmillan, 1983.

11 Power C, Manor O, Fox J. Health and class, the early years. London: Chpman and Hall, 1991.

2 Power C, Peckham C. Childhood morbidity and adulthood ill health. F Epidemiol Comm Health 1990; 44: 69-74.

3 World Health Organisation. International classification of World Health Organisation. International clas

14 World Health Organisation. International classification of impairments, disabilities and handicaps: a manual of classification relating to the consequences of disease. Geneva: WHO, 1980

15 Office of Population Censuses and Surveys. General household survey 1989. Series GHS no 20. London: HMSO 1991: 99-103.

16 Office of Population Censuses and Surveys. General household survey 1981. Series GHS no 11. London: HMSO, 1983

17 Office of Population Censuses and Surveys. Mortality statistics-cause 1980. Series DH2 no 7. London: HMSO, 1982.

18 Ross E, Peckham C, West P, Butler NR. Epilepsy in childhood: findings from the National Child Development Study. BMF 1980; 280: 207-10.

19 Scott PP, Willis PA. Road casualities in Great Britain during the first year with seat belt legislation. Department of Transport. TRRL Report RR9. Crowthorne: Transport and Road Research Laboratory, 1985.

20 The Secretary of State for Health. The health of the nation. A strategy for health in England. London: HMSO, 1992. 